\title{
EL JUEGO DE LA DERIVA CONTINUA ${ }^{1}$ THE GAME OF UNLIMITED DRIFT
}

\author{
Claudia Sofía Benito Temprano \\ Universidad Autónoma de Madrid
}

\section{ABSTRACT}

The following paper seeks to reflect upon different questions regarding literary interpretation. From an educational perspective as well as a theoretical point of view, this essay will revisit some of the primary considerations that should be taken into account by anyone willing to teach others how to read literarily; that is, semantics and pragmatics, as well as ethics - matters that bias individuals when creating the meaning in literary reading. Meanwhile, the author will attempt to remark the value of using texts instead of just interpreting them.

Key words: Literary interpretation, literacy, reading, reception.

\section{RESUMEN}

En el presente artículo se propone una reflexión en torno a distintas facetas de la interpretación literaria. Desde una perspectiva docente, pero también desde un punto de vista teórico, se sugiere una revisión de algunos de los aspectos que habría de tomar en

1 Esta publicación es resultado de investigación realizada en el proyecto de investigación de referencia PGC2018-093852-B-I00, proyecto financiado por el Ministerio de Ciencia e Innovación de España y por la Unión Europea. 
consideración todo aquel que se propusiese instruir a otros individuos en el ámbito de la alfabetización literaria: cuestiones semánticas y pragmáticas, pero también éticas, que afectan a nivel individual en la formación de sentido suscitada durante una lectura literaria. En segundo plano, se intenta legitimar el uso (no meramente interpretación) de los textos por parte del lector.

Palabras clave: Interpretación literaria, alfabetización, lectura, recepción.

Fecha de recepción: 8 de septiembre de 2021.

Fecha de aceptación: 23 de noviembre de 2021.

Cómo citar: Benito Temprano, Claudia Sofía (2021): «El juego de la deriva continua», en Actio Nova: Revista de Teoría de la Literatura y Literatura Comparada, 5: 255-284.

DOI: https://doi.org/10.15366/actionova2021.5.012 
Parte del quehacer profesional del teórico literario es redactar artículos académicos. Esta labor, aparentemente sencilla, implica un sinfín de problemas a veces no fáciles de dilucidar: entre otras cosas qué es un artículo académico, o qué puede valer como tal. Parece que empezar a definir lo que vale por «artículo académico» de teoría literaria podría incluso convertirse en objeto de una tesis doctoral inscrita en el ámbito de la teoría de géneros literarios o de géneros discursivos. Por lo que la mayor parte de profesionales en este ámbito eludimos esta responsabilidad definitoria y nos fiamos de nuestro instinto: igual que sabemos (más o menos) reconocer un artículo académico cuando lo vemos en una revista, pensamos que sabremos escribirlo.

Como persona preocupada por las palabras que soy, sin embargo, yo no puedo evitar girarme una y otra vez, mientras escribo, a eso de académico. Y lo despliego. Etimológicamente hablando, el académico tiene dos caras: por un lado, está revestido por la autoridad que otorga la pertenencia a una sociedad o comunidad de expertos; desde ese lugar suyo epistemológicamente privilegiado, «lejos del pueblo», tiene por otra parte una obligación formativa y docente. Tomando en consideración estas dos vertientes de la Academia, entiendo entonces que al producir un artículo hemos de tener en consideración nuestra vinculación con el saber de otros expertos y nuestro deber para con aquellos que no lo son. Me pregunto entonces si un artículo no debería de ser a la vez un documento técnico y una pieza de conocimiento «transpuesta» didácticamente: un texto con varias capas de comprensión, un exponente de esa «tercera cultura» de la que hablaba Brockman (1995).

Pero intentar poner a disposición de un público general los dilemas que subyacen a una de las muchas cuestiones de las que se preocupa la Teoría de la literatura es complejo, y más si se intenta no perder rigor —el rigor académico1 es difícil de conjugar con el rigor académico2-. Voy a pensar entonces en las cosas que a mí me han servido para aprender y en las que creo que me son útiles a la hora de enseñar. Sin ponerme demasiado nostálgica, me recuerdo cuando era estudiante. Rememoro las cosas que me gustaban y las que no, y me río a la vista de los conocimientos presentes descubriendo en alguna de aquellas cosas sentidos nuevos. En un extremo de mi memoria se encuentra la lectura de apuntes polvorientos en los que se desgranaba la interpretación biografista de obras literarias que nunca llegué a leer. En el otro, largos debates irreverentes sobre la valoración de un breve texto literario (que sí leí, y varias veces) sostenidos durante el tiempo de un seminario con otros compañeros, bajo la mirada aparentemente ausente de un docente silencioso. 
En aquellos seminarios, creo, empecé a aprender a leer reflexivamente, de forma consciente: y en este artículo pretendo verbalizar las ideas que he ido construyendo en torno a la interpretación y la didáctica partiendo de algunas de las herramientas y nociones que comencé a vislumbrar entonces. Espero se me disculpe si no lo hago de una forma demasiado ortodoxa; intentaré por lo menos que el trance no sea excesivamente arduo. Se tratará por tanto de abordar una preocupación académica: el tema de la interpretación literaria. La cuestión se desgrana al menos en las siguientes preguntas. Cómo enseñaría yo a leer. Cómo leo yo. Por qué leo como leo, por qué entiendo las cosas como las entiendo. Por qué leer para mí puede constituir tanto una actividad de ocio como una obligación laboral. Qué une la estética y la información. Cómo no ser prescriptivista al enseñar a mis alumnos a leer, cómo dejarles la libertad para que se labren un «estilo propio», unas ideas personales y un gusto «desclichetizado». Cómo lograr que lean sin obligarles a hacerlo, y cómo hacer que disfruten con el canon occidental (que acaba siendo ineludible en algún momento de la vida del filólogo) y que sepan a la vez mirarlo con sospecha.

Voy a partir de una comparación de la literatura con el ámbito del juego que no es propia. Es de hecho bastante frecuente y tiene detrás una bibliografía prolija y compleja. El origen de esta comparación surge posiblemente de un conjunto de observaciones bastante sencillas. Podríamos decir que hablar de literatura como juego sugiere al menos las siguientes ideas, algunas de ellas incompatibles entre sí:

1. La literatura es una forma de entretenimiento (como los juegos).

2. La creación es una forma de competición; hay participantes (autores) a los que se les da mejor que a otros (como los juegos).

3. La literatura sigue unas reglas o convenciones de creación y de lectura (como los juegos).

4. La literatura puede desenvolverse sin embargo de infinitas maneras, dando lugar a resultados finales inesperados (como los juegos).

5. La literatura está ligada a un cierto grado de azar (o de «genialidad») difícilmente comprensible racionalmente (como los juegos).

6. Para disfrutar la literatura, hay que tomarse en serio la lectura (como los juegos).

7. La literatura puede disfrutarse grupalmente (como los juegos).

8. La literatura puede disfrutarse en solitario (como los juegos).

9. La literatura ayuda a construir comunidad (como los juegos). 
10. La literatura involucra muchas veces la ficción (como los juegos).

11. La literatura se mantiene «al margen de la vida cotidiana» (como los juegos). $\cdots$

Dejemos abierto el conjunto de ideas suscitadas por esta comparativa.

A la vista de esta pequeña enumeración, suceden dos cosas que convierten la comparativa en problemática. Por una parte, «los juegos» son una realidad bastante variable. Es decir: hay tipos muy distintos de juegos. Con respecto a la afirmación [2], por ejemplo, podremos argumentar que hay juegos que no son competitivos, como por ejemplo los puzles; con respecto a la afirmación [7], podemos mantener (y así lo hacemos en [8]) que hay juegos que no son grupales, como los solitarios. Por lo tanto, hemos de tener en cuenta que, al igual que hay tipos bien distintos de juegos, es posible que haya tipos bien distintos de literatura. Y, además, al igual que hay formas bien distintas de jugar, hay formas bien distintas de escribir, y de leer, pues no todo jugador busca lo mismo en el ámbito de lo lúdico, y no todo lector tiene los mismos hábitos lectores.

Como añadido, cabe aclarar que estas características de los «juegos» son extrapolables no solo a la literatura, sino a todo lenguaje, y podría decirse que a toda comunicación lingüística. A quien desee saber más sobre esta cuestión le remito a la fructífera teoría wittgensteiniana de «los juegos del lenguaje».

Dejando en suspenso estos problemas, que complejizan mucho una comparativa que nacía con el mero fin utilitarista de vislumbrar distintas facetas de lo literario, vamos a la cuestión central. En lo que más se ha fijado la teoría es quizá en el rasgo [3], la que atañe a la literatura como un conjunto de reglas. Hablamos de la «imaginación domada», hablamos de un «sistema de modelización secundaria», hablamos de «reglas constitutivas» o de «reglas regulativas». Parece que para enfrentarse a todo este juego de la comunicación haga falta una gramática universal o una gramática de la ficción o una gramática de la fantasía que nos explicite cómo hay que hacer las cosas para hacerlas bien.

Lo curioso de todo es que, a pesar de tratar de imponer todas estas reglas, normas, principios... valoramos positivamente a los tramposos. La «innovación estética» es un valor positivo. Qué mejor que una Rayuela que se salta todo orden, qué mejor que un Tristam Shandy, qué mejor que un Lazarillo de Tormes. Son obras que subvierten las reglas del juego que se habían tenido hasta el momento como principales. Dejamos a los autores incluir grandes peripecias, implementar estrategias que, con un poco de azar (genialidad, suele decirse) y 
mucho saber hacer, consiguen pasar inadvertidas, fascinarnos. Al fin y al cabo, el «trile» es también un juego. En «The Art of Fiction», Henry James justifica el desviamiento de la regla: «The only obligation to which in advance we may hold a novel without incurring the accusation of being arbitrary, is that it be interesting» (1884: 60). Mientras resulte interesante, qué más da que su composición resulte arbitraria.

$\mathrm{Y}$, sin embargo, a nuestros alumnos, muchas veces les hacemos transitar la ruta interpretativa de nuestra literatura nacional a golpe de contextualización histórica e intertextualidad destripada. Les hacemos creer que leer es como resolver un acertijo para el cual hay una única respuesta, y al hacerlo ejercemos de padres castradores. De algún modo, nos parece innecesario mencionar que «el significado literario vive y se forma en la tradición múltiple ininterrumpida» (García Berrio 1994: 249) y que lo que estamos haciendo al insistir en un canon ya leído y releído es perpetuar esa tradición, mantenerla así, ininterrumpida, nada más ni nada menos. Cuando eludimos esta responsabilidad nacional-tradicionalista para despertar el carácter lector (individual) de nuestros estudiantes, tratamos de no dar nuestra opinión, de no intervenir demasiado. Y entonces pasamos por vagos, por despreocupados... o por gallegos. Si somos habilidosos, utilizamos las reglas que se nos han impuesto para decir lo que creemos correcto, y entonces actuamos de forma valiente —decía Shklovsky (2005 [1923]) - , recorriendo nuestra vida académica tortuosamente, como un caballo por un tablero de ajedrez. Explicamos todo eso que está en el currículo tradicional, todo ese must know, para luego empezar a desarmarlo desde abajo como bien podemos. Y decimos «esto quiere decir aquello» y «la $m$ con la $a$ se dice ma», pero mientras tanto anticipamos la manera de incitar al alumno (al lector) a la reflexión deconstructiva, a la mirada criticona: cantamos las reglas, pero también le damos un libro de jugadas con la intención de que aprenda a jugar, que es (creo yo) lo más interesante.

Lo que más me preocupa en este momento, por lo tanto, es: por qué es tan común en las clases de literatura la marginalización del lector. Por qué se da con tanta frecuencia este adoctrinamiento, esta puerilidad. Al menos en el ámbito escolar parece que nos resistimos a abandonar el elogio a una autoridad textual que nos mantiene seguros en nuestro camino humanístico de inspiración positivista. ¿Por qué no dejamos jugar de una vez a nuestros yoes receptores?

$$
* * *
$$

El único motivo que se me ocurre para esta práctica tan autocontenida de la lectura es la indistinción de los diferentes tipos de interpretación en que se ve inmerso el ser humano. 
Parecería que, si nos damos la libertad de leer como queramos, pronto nos veremos sumergidos en la mentira, en las fake news, en la incomprensión de la historia, en las religiones paganas, las lecturas de tarot y la deconstrucción de la propia identidad, que se demuestra ridícula ante la incapacidad lectora del sujeto. Leer bien es la única forma de alcanzar una verdad que se sitúa debajo de los signos. Una verdad única y positiva. Una verdad autorizada, traducida en la escritura a palabras objetivas y claras que, siempre que eludamos el juego, nos permitirán aprehenderla. «Una verdad para gobernarlos a todos, una verdad para encontrarlos, una verdad para atraerlos a todos», etc.

Como meterme en este berenjenal acerca de lo que puede o no contener algún tipo de «verdad» y de lo que se quiere decir cuando se habla de verdad supera mis aspiraciones momentáneas (y podría ser visto además como una incursión ilegítima y excesivamente aventurera en el ámbito de la epistemología), voy a entender, al menos por el momento y con una finalidad práctica, que existen distintos géneros de interpretación, como sugiere Iser $(2005 \text { [2000] })^{2}$. Que no todos los tipos de discurso son susceptibles de ser interpretados por medio de los mismos mecanismos, si se quiere que esos textos cumplan la función sociocultural para la que fueron creados. Lo que puede servir para interpretar un conjunto de textos religiosos (por ejemplo), y formarse un pensamiento teosófico y una identidad en el marco de este pensamiento, no sirve para interpretar un conjunto de textos históricos y analizar de forma crítica los mecanismos de causalidad que han generado el estado de las cosas actual; tampoco esto servirá de cara a la lectura de un texto legal, ni para dictaminar una sentencia en base a este texto; y por cierto, casi con toda seguridad podría decirse que esta manera de leer será del todo inadecuada a la hora de interpretar un modelo científico

\footnotetext{
$2 \mathrm{Si}$ alguien se queda con curiosidad con respecto a lo que yo pienso sobre esta cosa de la verdad de lo escrito, creo que lo mejor que puedo hacerle es remitirle a los capítulos 25 a 29 de Metáforas de la vida cotidiana de Lakoff y Johnson (2012 [1980]), a las ideas de Dewey, a Pragmatism, de Willam James (1922 [1907]) y a «The Fabrication of Facts», de Nelson Goodman (1989 [1978]). Y sobre la terrible importancia de estas reflexiones acerca de la interpretación y la verdad, me permito incluir aquí un extracto escrito por Gregory Bateson:
}

El lenguaje afirma de continuo, mediante la sintaxis de sujeto y predicado, que las «cosas» de alguna manera «tienen» cualidades y atributos. Una manera más precisa de hablar insistiría en que las «cosas» son producidas, en que se las concibe separadas de otras «cosas», y en que sus relaciones internas y su comportamiento en relación con otras cosas y con el hablante son lo que las torna «reales».

Es preciso tener bien en claro esta verdad universal: sean lo que fueran las «cosas» en su mundo pleromático y cosístico, sólo pueden ingresar en el mundo de la comunicación y del significado merced a sus nombres, sus cualidades y sus atributos (o sea, merced a informes sobre sus relaciones internas y externas y sobre sus interacciones). (2002 [1979]: 74) 
(climático, por ejemplo) y generar previsiones meteorológicas. A la vista del símil «leer es como jugar», podríamos decir que la lectura literaria es más fuertemente lúdica que otros tipos de lectura, que tiene más rasgos en común con los juegos (rasgos incluso contradictorios, como decía).

Estos géneros de interpretación (científica, legal, religiosa) son convencionales y su objeto de interpretación está determinado por una serie de tradiciones y costumbres y por un conjunto de valores que hemos aprendido como colectivo cultural y que nos hacen verlos como cosas distintas (sin entrar tampoco a valorar si efectivamente los objetos de cada género de interpretación son cosas ontológicamente distintas u objetivamente distintas, siquiera). $\mathrm{Y}$ es que, posiblemente, a estos géneros de interpretación se les han asignado diferentes funciones dentro de nuestra comunidad.

Ahora bien, si interpretar de manera literaria se asemeja, como hemos dicho, a jugar, es posible pensar en muchas funciones distintas de lo literario. Incluso en un tipo de interpretación literaria que, como los juegos, suceda al margen de las convenciones habituales, que se fundamenta en una función no esclarecida. Que consista únicamente en el leer «como si». Y que aplique ese género de interpretación a un texto para el que «en el mundo habitual» $\mathrm{O}$ «la realidad normal» $\mathrm{O}$ «la realidad habitual» (expresiones todas ellas que utiliza Huizinga en su definición formal del juego, 1972 [1954]: 26) no sería pertinente. Una lectura literaria consistente en actuar, en el camino entre casa y el trabajo, de acuerdo con la premisa de que el suelo es lava, o que no debemos pisar las baldosas impares, o que los tocones de los árboles talados la semana pasada son oseznos jugando a las «figuras»o «actitudes» del «Final del juego» de Cortázar. ¿Para qué? Esa es la cuestión.

En tiempos recientes, se viene llamando cada vez más la atención sobre la existencia de distintas escuelas interpretativas, o comunidades interpretativas, como las denomina Fish (1980). Podríamos decir que estas comunidades se distinguen porque enseñan a leer de formas distintas. Tienen distintas reglas para jugar a juegos que comparten tablero. Buscan la verdad del hecho literario de diferente manera, porque la entienden como cosas distintas. La diferencia entre los miembros de estas escuelas radica en que plantean distintas metas a sus jugadores. Al perseguir un fin distinto, los miembros de las diferentes escuelas se fijan variados objetivos, apoyados en sistemas de valores alternativos, y en ese sentido cambian sus estrategias, lo que consideran susceptible de ser leído literariamente, los efectos de la literatura, el prestigio social que se le otorga a lo literario... Dentro de cada escuela, claro, 
seguirá habiendo intérpretes a los que se les dé mejor el juego: habrá jugadas más elegantes o efectivas que otras. Pero, si dos jugadores están jugando de acuerdo con distintas instrucciones, ¿cómo vamos a comparar sus juegos? ¿Qué sentido tiene hacerlo?

Encontrar un ejemplo literario desde el cual explicarles esto a mis alumnos es complejo y acaba requiriendo de resúmenes y paráfrasis altamente insatisfactorios, por este motivo he decidido hacer un esfuerzo de reformulación académica (de ahí toda la cuestión del juego: la gamificación está muy de moda ahora en el ámbito educativo) para recurrir a viñetas cómicas. Esta idea de que los jugadores (lectores) podemos enfrentarnos al texto (tablero de juego) con distintas reglas y pasarlo igualmente bien jugando, cada uno a nuestra manera, se la debo a Quino:
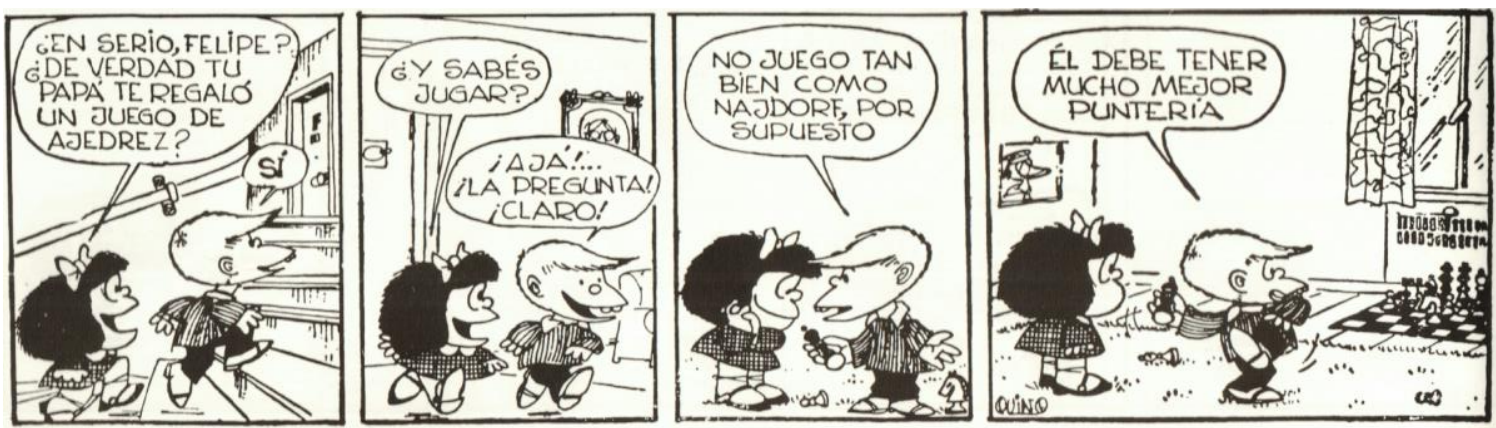

Referencia: Quino, Todo Mafalda, Barcelona, Lumen, 2003: 64.

Felipe «sabe» jugar, porque Felipe no juega al mismo ajedrez que Najdorf. Estoy segura, no obstante, de que su juego es en cierta medida satisfactorio. ¿No es acaso satisfactorio jugar a los bolos, a la petanca o a los «gogos»? Su juego, aunque no utilice las reglas tradicionalmente aprendidas para los movimientos de las fichas del ajedrez, tiene también unas reglas, del tipo «el que más piezas logre derribar en un lanzamiento gana» y «hay ciertas piezas que son más elaboradas o menos abundantes y dan más puntos al ser derribadas que otras». El juego original ha perdido su especificidad: Felipe no juega al ajedrez, o no juega a lo comúnmente conocido como ajedrez: ha inventado unas nuevas reglas, caprichosamente. Y que no suene esto a ridiculización de una práctica lectora alternativa. En la literatura es en cierta medida aplicable la máxima de que el cliente siempre tiene la razón. A veces, en el mundo de la teoría se nos olvida que la mayor parte de lectores literarios leen por leer, y que no hay nada importante (a nivel vital) involucrado en su lectura. No es que su lectura sea banal o esté desprovista de sentido: es que el cuerpo de reglas de juego que introducen estos lectores de forma orgánica les permite extraer un disfrute espontáneo, convirtiendo su quehacer en un pasatiempo agradable y poco complicado. Es esta falta de complicación la que parece convertir sus interpretaciones en más simples, menos virtuosas. 
Su lectura, en cierto modo desprovista del halo de sacralidad que reviste la de aquellos que buscan la sublimación en lo literario, exige la diversión, y hace primar el «abandono» sobre el «éxtasis» (también sobre la conexión entre sacralidad y diversión son pertinentes aquí las reflexiones Huizinga, 1972 [1954]). Pero, si lo importante para este lector es el disfrute, ¿acaso importa cómo acceda a esta delectación?

De igual modo que el adulto supervisa el juego de los niños sin interferir en él más que para evitar daños —físicos, psicológicos o de mobiliario-, observándolo con la mayor de las curiosidades, el teórico puede situarse al margen de la página para mirar con atención a la madre, el hermano, las alumnas... que leen. Sin embargo, la práctica docente en lo referente a la lectura (eso que los americanos llaman literacy y que aquí tendríamos que llamar «literaturización», o «alfabetización literaria») se asemeja más a la del árbitro que controla con atención la posición de los jugadores para comprobar que no se produce un fuera de juego.

Creo que esto ocurre así en parte por eso de la verdad que he intentado eludir antes y que voy a esquivar de nuevo, y en parte por la función que asignamos hoy en día al arte (y, por tanto, a la literatura). La mistificación de lo estético nos ha convertido en censores de toda práctica que no iguale en sofisticación a los objetos con los que interactúa. La mirada apocalíptica es la que se hace eco de esa pieza de saber popular que reza que «no se hizo la miel para la boca del asno» y que se esfuerza por seguir disfrazando a sus borricos de jamelgos a ver si así se revaloriza la industria apícola. Pero el apocalíptico parece ignorar que los cerdos (animales igual de deleznables que los asnos, según la opinión popular) son los que mejor identifican la fina esencia de la trufa negra.

Bien es verdad que en esta sociedad valoramos que nuestros congéneres actúen sabia y racionalmente. Que no pequen de ingenuos, que por lo menos intenten pensar en cómo hacen las cosas y por qué. Y la labor del docente debería ser esa: coger al Felipito de turno por las solapas y, sin entrar a valorar si su lectura es mejor o peor que, pedirle que explique cómo la hace, qué saca de ella, qué reglas utiliza para hacerla: qué juego se ha inventado a partir de los materiales disponibles. Porque es verdad que

[s]in reglas los juegos perderían su especificidad, no habría sino un único juego consistente en quebrantar las reglas a capricho de cada cual; la invención del juego, en cambio, es la invención de las reglas, del algoritmo que cada uno desarrolla, y al hacerlo, establece un contacto profundo y autoconsciente con el mundo posible que él mismo contribuye a formar. (Núñez, 1992a: 441) $* * *$

Pero, si tuviese que explicar la cuestión de las «comunidades interpretativas»con ejemplos literarios y sin demasiada exhaustividad, me gustaría recurrir a un texto autóctono: 
el Lazarillo de Tormes. Mi formación en filología hispánica me ha puesto en conocimiento de dos tipos de teorías alternativas: las que contemplan el Lazarillo como una sátira, escrita evidentemente por un autor que no se identificaba a sí mismo con Lázaro de Tormes (y por tanto estamos ante un texto anónimo) y las que lo ven como una larga epístola autobiográfica (autorizada por tanto por Lázaro de Tormes). La versión ortodoxa vs. la de (por ejemplo) Rosa Navarro Durán (2004).

Me gustaría relatar esto y preguntar a mis alumnos qué creen que pensarán los alumnos de Rosa Navarro Durán y qué creen que pienso yo del Lazarillo, y, para rizar un poco más el rizo, qué creen que pensaríamos unos y otros si no supiésemos de la existencia más que de nuestra propia teoría. Y a partir de ahí, me gustaría generar debate sobre lecturas más o menos históricas, lecturas negociadas... Pero, ¿qué me pasa con el Lazarillo? Que es un mal ejemplo. No quiero culpar a nadie del desconocimiento de una u otra obra literaria: ¿acaso es posible tener un dominio total de la cultura que se ha ido acumulando dentro del «canon» tradicional a lo largo de casi treinta siglos? Me hago la pregunta inocentemente y evito traer a colación la falta de atractivo del discurso que emiten algunos difusores de la tradición literaria.

No voy a pensar que mis alumnos no disfrutaron el Lazarillo y que por tanto no lo recuerdan porque alguien les arruinó la diversión con complicadas elucubraciones históricas o con listas numéricas y sinopsis de capítulos malamente memorizadas -1-ciego, 2-clérigo de Maqueda, 3-escudero, 4-fraile de la merced... ¿`sabría el autor del Lazarillo que sus personajes iban a ser tan y tan y tan recordados?-. Tampoco voy a sospechar de ellos, que con esa vagancia juvenil y esa picardía tan suya se conocen bien el Rincón del Vago, la Wikipedia, los apuntes de la hermana mayor y YouTube, y han desistido del disfrute genuino del estilo literario para sustituirlo por la ingesta glotona y poco nutritiva de argumentos resumidos. Haciendo examen de conciencia, me pregunto: ¿de verdad es importante contarles a los estudiantes que hay quien ha interpretado que cuando Lázaro dice que abandonó al fraile de la merced porque se le gastaron los zapatos «y por otras cosillas que no le gustaron» está insinuando que era víctima de abusos sexuales?

En todo caso, creo que es importante hablar de la formación individual y de la escolarización para explicar cómo la sociabilización lectora (la literacy) influye en nuestra manera de leer. Y la valoración de las distintas interpretaciones que llevamos a cabo desde un mismo texto tienen que ver con los principios epistemológicos imperantes en nuestro contexto sociohistórico. 

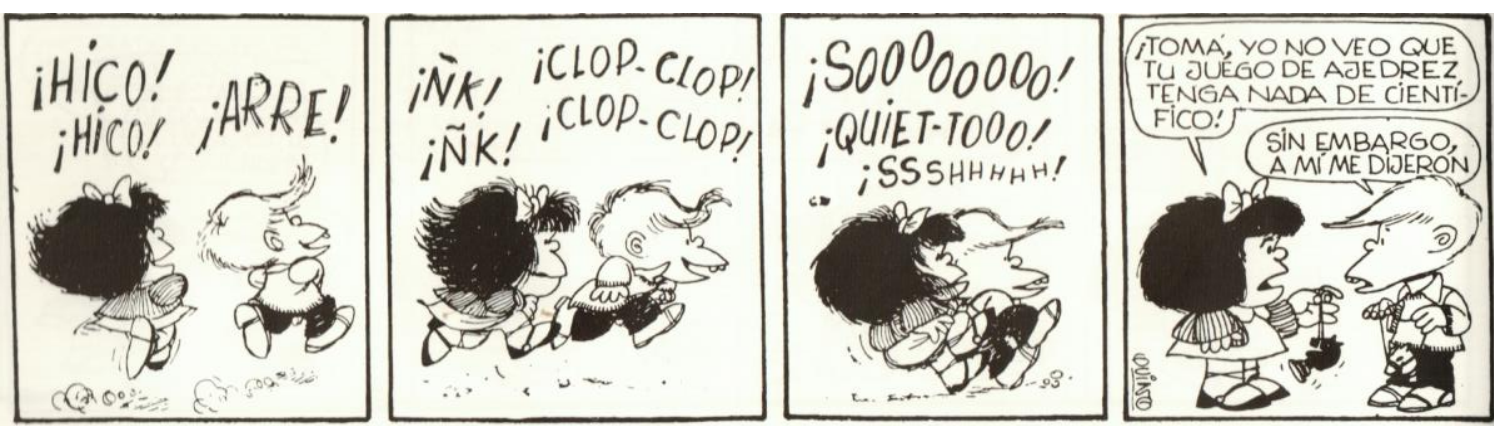

Referencia: Quino, Todo Mafalda, Barcelona, Lumen, 2003: 64.

La cara de Mafalda en la última viñeta me parece representativa: esperaba encontrarse con un juego estimulante, de fondo científico, seguramente a raíz de algo que le haya contado Felipe. Pese a que ha disfrutado jugando de esa manera de la que saben ellos jugar intuitivamente (con unas reglas ya sabidas), no ha logrado encontrar la «cientificidad» de que se supone el juego está revestido. Dado el valor (epistemológico, cognitivo, político...) que asignamos a las cosas científicas y a la ciencia, el descubrimiento de que una forma de lectura no está investida de cientificidad la relega a un segundo plano. Quizás el uso del caballo de Mafalda y Felipe sea más divertido, deportivo, original, estimulante... que el movimiento tradicional en el tablero, pero al no ser «científico», no vale. Mafalda valora el ajedrez desde la expectativa generada por la comunidad sobre la «utilidad» o «finalidad» del juego; al no ver realizado este valor, que además está en alza en la cosmovisión de esa comunidad, el juego (su juego y $s u$ forma de jugar) se torna insuficiente, insatisfactorio.

Si en la escuela interpretativa (en la «escuela ajedrecística») de Mafalda y Felipe hubiese habido una asociación del ajedrez con la producción de endorfinas, el movimiento, la libertad, la creatividad... seguramente hubiesen reevaluado su propio desempeño en este juego. Sin embargo, los saberes comunitarios que rigen la valoración y la práctica lectoralúdico-deportiva tienen tanto peso sobre los niños que los preparan para una forma de leerjugar determinada. Cuando no logran ejecutar esta práctica lecto-lúdica (y Mafalda y Felipe no consiguen jugar «bien» al ajedrez porque nadie les ha enseñado los movimientos, la meta del juego ni sus reglas), el sentimiento de fracaso es similar al del lector que no interpreta una metáfora del modo en que le dice su maestra que debería hacerlo.

Las reglas básicas de la comprehensión literaria —como la llama Ingarden (2005 [1968]) — vienen a suponer que, en el juego literario, la lectura va más allá de la captación del sentido de las distintas oraciones. La lectura necesita de una participación «activa», que viene a ser lo mismo que la participación imaginativa en el juego. Como lectores, utilizamos las 
reglas que conocemos para analizar la ficción. Valiéndonos de estas reglas y de los materiales significativos que se nos dan a modo de estímulos externos u objetos interpretables, aglutinados en un mensaje bien delimitado, participamos de la co-creación de la obra. Vamos más allá de las palabras, más allá de su materialidad inmediata: encontramos que nos indican un significado que construyen en la recámara de nuestro cerebro una historia a la que nosotros asociamos un valor. Una historia que, por otra parte, sabemos que no es verdad, que tiene una cualidad opalescente (el término es de Ingarden, 2005).

Un problema que a veces puede surgirle a lector desinteresado (en el mal sentido de la palabra), o apático, es que no sea capaz de superar el plano primario. Que no «entre» en el juego. Que no suspenda su incredulidad y su escepticismo. Que se quede en las palabras, y no llegue a «concretizar» la historia, que no alcance la imagen, o la metáfora, o todo lo que puede esconderse detrás de un trazo de tinta. Que choque contra ese cristal translúcido de lo opalescente y se quede en la literalidad, o que ni siquiera alcance esta y se tropiece en la búsqueda de significados convencionales. Creo que las siguientes viñetas explican esta idea:
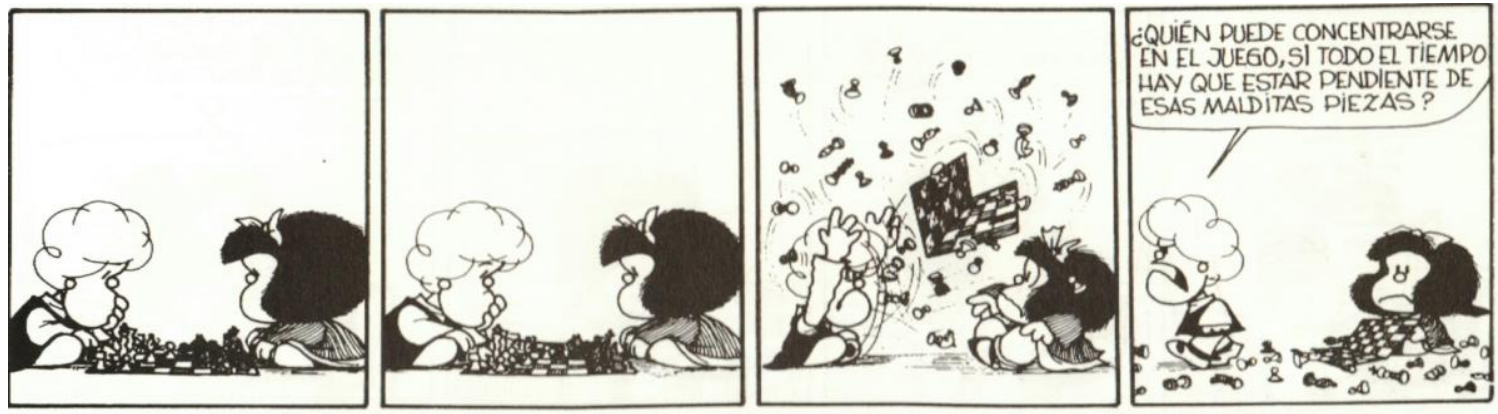

Referencia: Quino, Todo Mafalda, Barcelona, Lumen, 2003: 395.

Pero incluso para esta necesidad de obviar lo inmediato para pasar a lo significado hay excepciones. Podemos hablar de multitud de intentos vanguardistas que tratan de llamar la atención sobre la propia materialidad de la palabra y sobre su aspecto gráfico, sobre su estética, sobre su aspecto. Textos que llaman la atención reflexivamente sobre el hecho de que son textos. Hay también textos en los cuales los personajes juegan a la incoherencia, y a mostrarse en tanto que personajes y meros personajes, y que reflexionan también acerca de 
su propia existencia personajística. En los que las narraciones son incoherentes para demostrar su voluntario desprendimiento de la «realidad» con que podría confundírselas.

Por otra parte, cabe justificar la barrera que para algunos lectores suponen los textos excesivamente complicados o (subjetivamente hablando, como siempre) mal escritos, o (y esto es todavía más subjetivo) mal editados, en los cuales impera la incomodidad de una tipografía mal seleccionada, un justificado injustificado o un papel demasiado sucio. Hay algunos lectores cuya patología interpretativa está causada por el formato e-book, o por la presencia virtual de un icono que da acceso a internet en algún punto de su dispositivo. Y hay otros que simplemente tienen familia, perro, gato, televisión o vecinos.
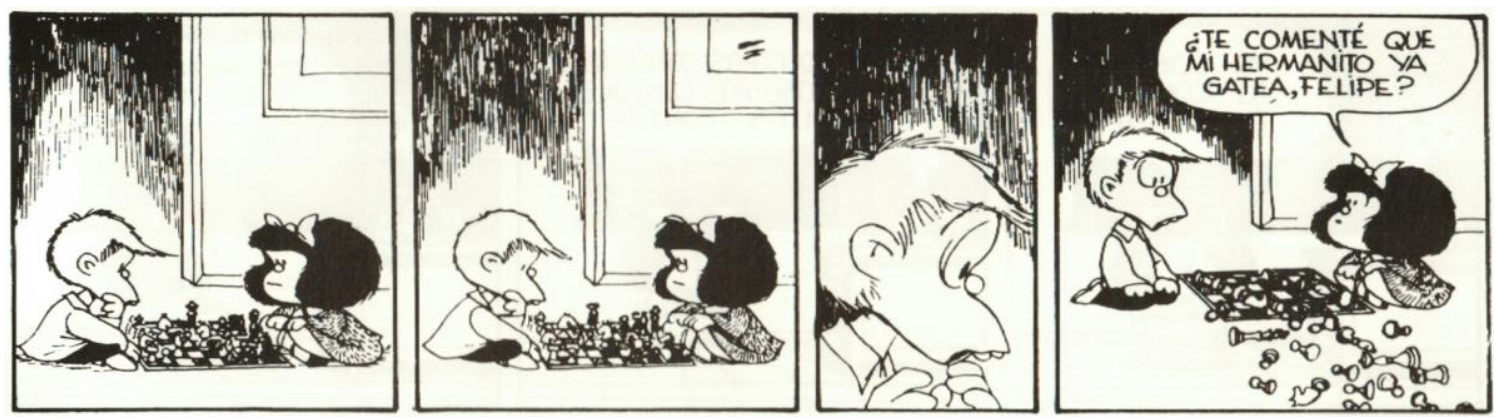

Referencia: Quino, Todo Mafalda, Barcelona, Lumen, 2003: 265.

Existe una tendencia generalizada a tratar de incultas u obtusas a aquellas personas que se quedan en lecturas muy superficiales: el alumno que interpreta una metáfora, o una ironía, o un juego de palabras como una expresión literal nos resulta inconveniente. Sin embargo, todos nos hemos visto envueltos en algún malentendido en alguna ocasión, y siempre es posible que el posterior descubrimiento de nuestra interpretación insuficiente/divergente/anormal (nuestra misinterpretation, que no es lo mismo que nuestra malinterpretación) haya causado un efecto de revelación, de descubrimiento postergado sobre nosotros. La ingenuidad a veces tiene consecuencias desoladoras para el cuerpo social.
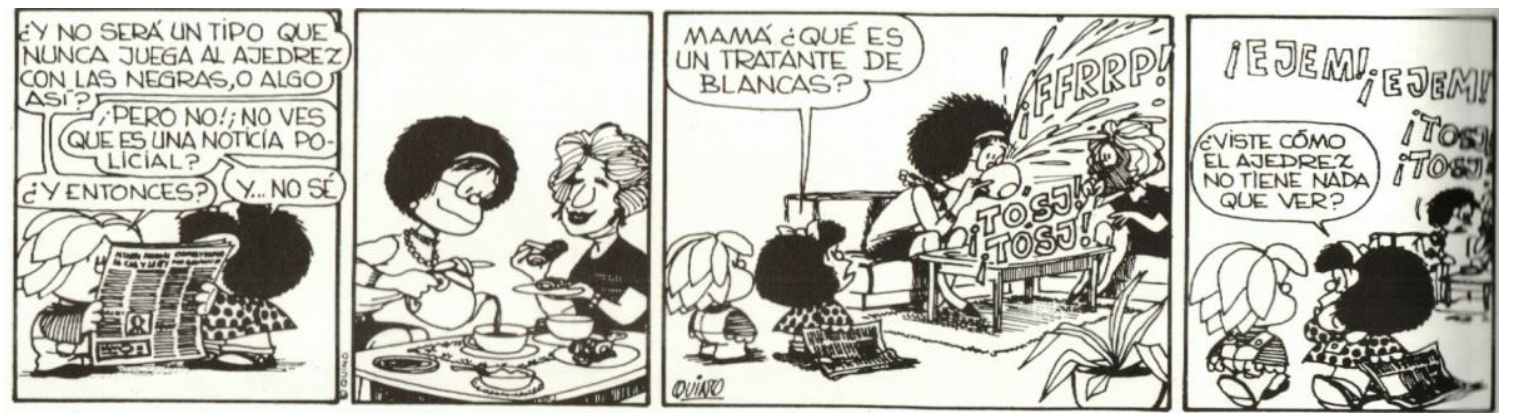

Referencia: Quino, Todo Mafalda, Barcelona, Lumen, 2003: 476.

No obstante, en un mundo de diccionarios y enciclopedia, de leyes, de normas y de normalidades lingüísticas, tampoco habría que presionar al lector literal; quizás sería más 
interesante preguntarle a la institución escolar cuál es, de forma inexacta, opalescente, taimada y verdaderamente literaria, el significado de las palabras. Y recordar esa idea en la que tanto se nos insiste a los docentes en formación de que la adquisición de competencias es gradual, es decir, que las reglas dan unas pistas esquemáticas de cómo habrá que desarrollar el juego, pero para ser brillante en el mismo hay que tener una práctica regular y autorreflexiva, que contemple la innovación como un valor positivo.

Hago un inciso con el fin de explicitar que, para que la práctica del lector pueda ser autorreflexiva ( $\mathrm{y}$ «mejorar» individualmente, forjándose su estilo propio), este debe ser consciente de que la interpretación es precisamente esto, una práctica. La idea de partida que yo presentaba y sobre la que se ha ido construyendo todo lo demás es que, aunque pueda decirse que un texto existe por sí solo (afirmación problemática en la que no voy a entrar), no funciona por sí solo. Hay que jugarlo. Las reglas de juego, si existen por sí solas (aunque sea en calidad de asunciones intersubjetivas), tampoco funcionan por sí solas. Tiene que haber unos jugadores que las pongan en marcha. Que interpreten estas reglas activamente (en el sentido de interpretar que se traduciría por play, jouer, spiel) para interpretar un texto literario (en el sentido de leer literatura que aquí nos ocupa, y que guarda una relación difusa y conflictiva con ese otro).
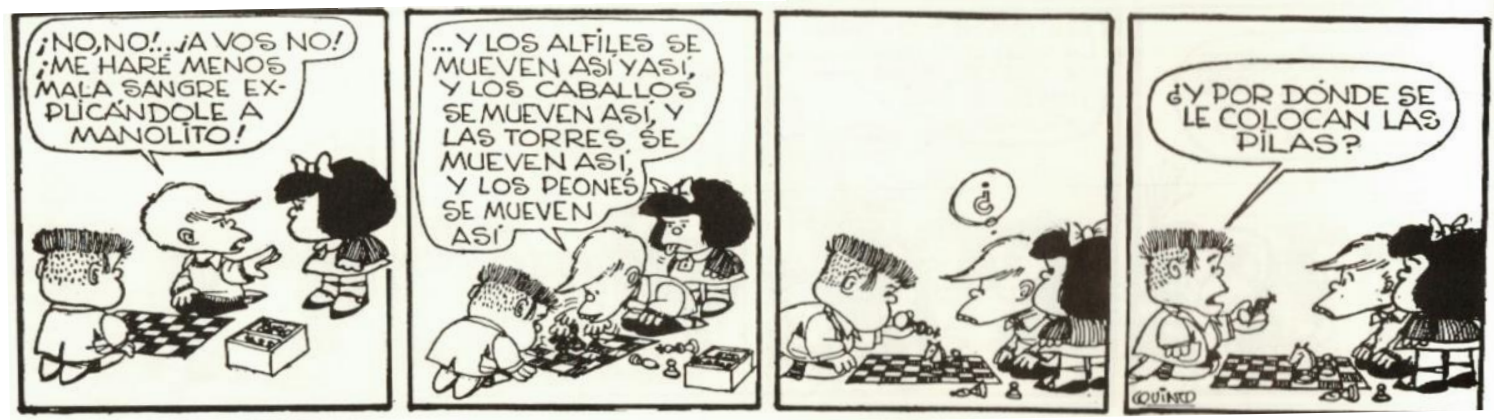

Referencia: Quino, Todo Mafalda, Barcelona, Lumen, 2003: 64.

Conviene recordarles esto a los lectores de vez en cuando para que se resitúen en su co-creación inconsciente de sentido. También para que, sabiendo que su individualidad está aportando presuposiciones, sean capaces de domar a su bestia adjudicadora de significado; también para que aprendan a cuidarla, alimentando sus gustos, valorando sus necesidades y ofreciéndole nuevos manjares nunca antes probados. 
En el momento en que adquirimos conciencia de la existencia de unas «reglas» de la lectura y conseguimos interiorizarlas, nos convertimos en intérpretes voraces. Nos pasa lo mismo que cuando aprendemos a manejar la palanca de marchas del coche y le cogemos gusto a la conducción. Cuando se nos explica cómo ha de ser la estructura de un soneto, por ejemplo, y cómo se suele organizar el contenido en sus estrofas, no es infrecuente que nos encontremos contando con los dedos mientras leemos cualquier poema, tenga o no cuatro estrofas, parezca o no visualmente un soneto. Pero puede ocurrir que la excesiva atención que precisa en un principio el coordinar manos y pies para el cambio de marchas acabe redundando en pequeñas distracciones (que esperemos no acaben en catástrofe pero que podrían).

Cuando aprendemos a ver lo que sucede por detrás de las grafías, al otro lado de esa opalescencia, empezamos a generar, queramos o no, expectativas. Al habernos enfrentado ya a un número relativamente alto de textos y de situaciones como las que se muestran en ese texto, hacemos cálculos probabilísticos. Anticipamos lo que sucederá, planificamos nuestra lectura. A veces, incluso sobreinterpretamos. En el quitar capas de la lectura tratamos de encontrar un concepto nuclear que a veces no llega a aparecer.
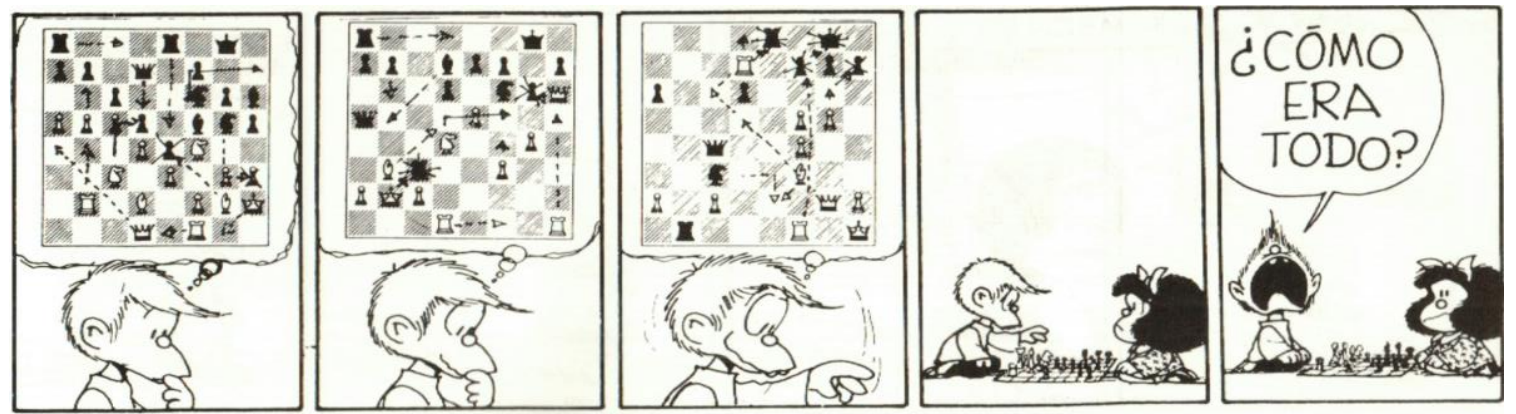

Referencia: Quino, Todo Mafalda, Barcelona, Lumen, 2003: 375.

Para inducir a la reflexión acerca de dónde hay que cortar la búsqueda de interpretaciones de un texto literario, creo conveniente hablar de dos herramientas «filosas». Pienso que en el acto de la interpretación uno debería tener presente la navaja de Ockham, porque me gusta la idea de que la hipótesis más sencilla seguramente sea la más adecuada. Esta idea me satisface enormemente porque me permite ser vaga en mis divagaciones y quedarme con las interpretaciones de los textos que me son más satisfactorias y me llenan más, sin tener que consultar la historia de la interpretación de cada libro que leo, sin tener que buscar cosas en la enciclopedia y sin tener que ir a las notas a pie de página a ver variantes e historia y estemas y... - por ejemplo- Pero sería una pena que con esa navaja cortásemos toda divagación y toda curiosidad: a veces el anecdotario nos aporta informaciones extra, que 
complementan al texto o que simplemente enriquecen nuestra experiencia aportando informaciones suplementarias. En la lucha por la interpretación hay textos punzantes - como La espada de los cincuenta años, de Danielewski (2014 [2005]) - que pueden con las reducidas dimensiones de la navaja de Ockham y que solo se despliegan por completo si ponemos de nuestra parte más de lo que está escrito. Hay también interpretaciones divagatorias cuya belleza merece ser tenida en cuenta frente a la «buena interpretación», la perezosa, la del lector racionalista — como la lectura que hace Nabokov de Guerra y paz (2010 [1981]), por ejemplo-.
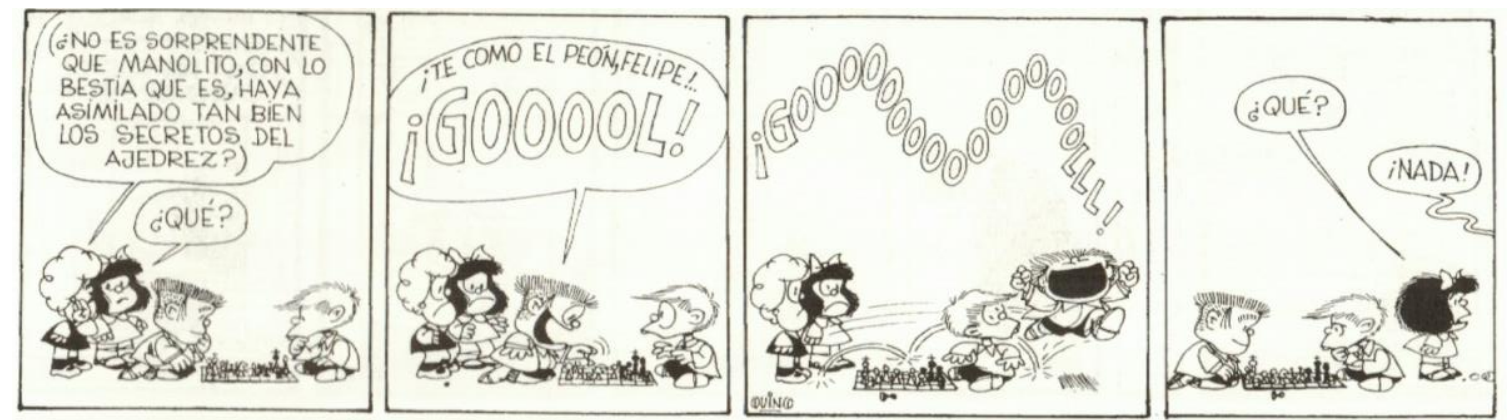

Referencia: Quino, Todo Mafalda, Barcelona, Lumen, 2003: 31.

Si el resultado de una lectura aparentemente muy rebuscada hace resonar algo, aunque este algo sea aparentemente erróneo, aunque esté fuera de lugar, aunque nos lo traigamos nosotros al juego y se lo sumemos, ¿cómo de malas pueden ser las consecuencias? Manolito, habiendo entendido las reglas del ajedrez, obtiene de sus avances en el juego el mismo placer que el futbolista cuando anota un gol. Utiliza esa capacidad humana consistente en mezclar cosas aparentemente muy distintas para conocer una sensación que le es nueva. A través de la analogía vive el ajedrez, lo incorpora, lo hace suyo. La expresión de alegría (su «gol!») le sirve para mediar con algo que le era desconocido. También mediamos a veces con la realidad a través de símbolos o metáforas, y no consideramos estas malas «traducciones», ni malas interpretaciones.

En la cuestión de la creación de expectativas y del «ir más allá de las palabras» y del leer desde la vagancia de un sofá alejado de la biblioteca universitaria, entra también la cuestión de la posición desde la que leemos. El contexto de lectura, en el sentido más amplio, es creado siempre por el receptor, que se enfrenta al texto literario en un momento de su vida, con un cuerpo de presuposiciones, experiencias y conocimientos aprendidos. Entre estos conocimientos podemos contar sus ideas con respecto a las reglas del juego interpretativo, lo que sabe acerca del libro (objeto y reproductible) que está manejando, 
acerca de su autor, de su historia, de su... (¿hasta dónde puede extenderse el paratexto?) También se incluyen en este apartado sus prejuicios con respecto a los distintos eventos que se adivinan en el más allá de las palabras, que son representados por ellas, que se relatan, o se narran. Su sentido común y su política personal:
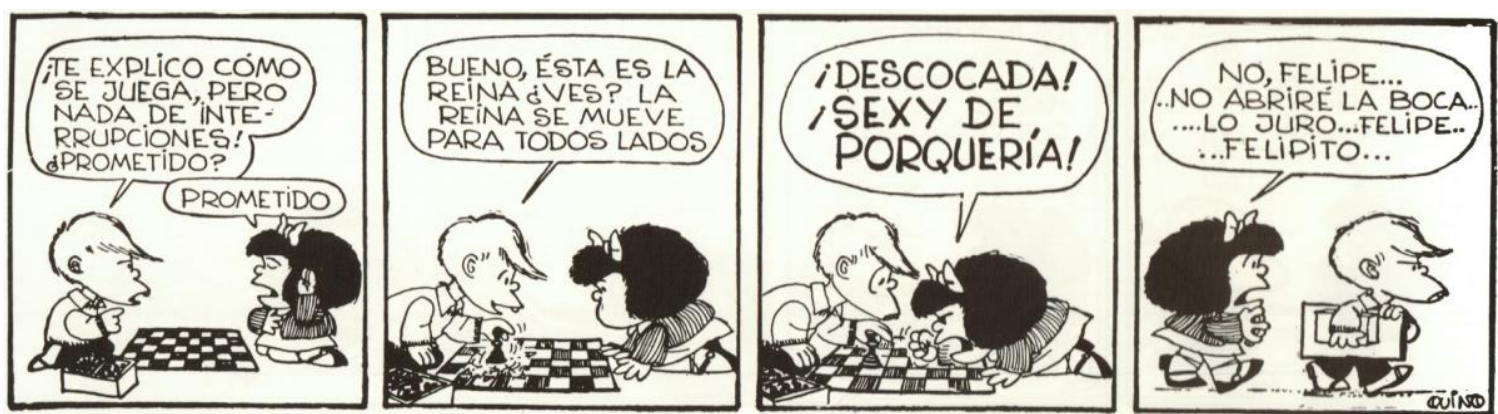

Referencia: Quino, Todo Mafalda, Barcelona, Lumen, 2003: 64.

En la tira, Mafalda se enfrenta a las reglas del juego con actitud sospechosa. No es capaz de ese «aislarse de lo cotidiano» que, decíamos, suele incorporar la interpretación (y que no es exactamente tal en la medida en que nosotros mismos nos hacemos compañía a lo largo de la cotidianeidad y del juego). Mafalda lee el juego seriamente, no se enfrenta a él con inocencia complaciente.
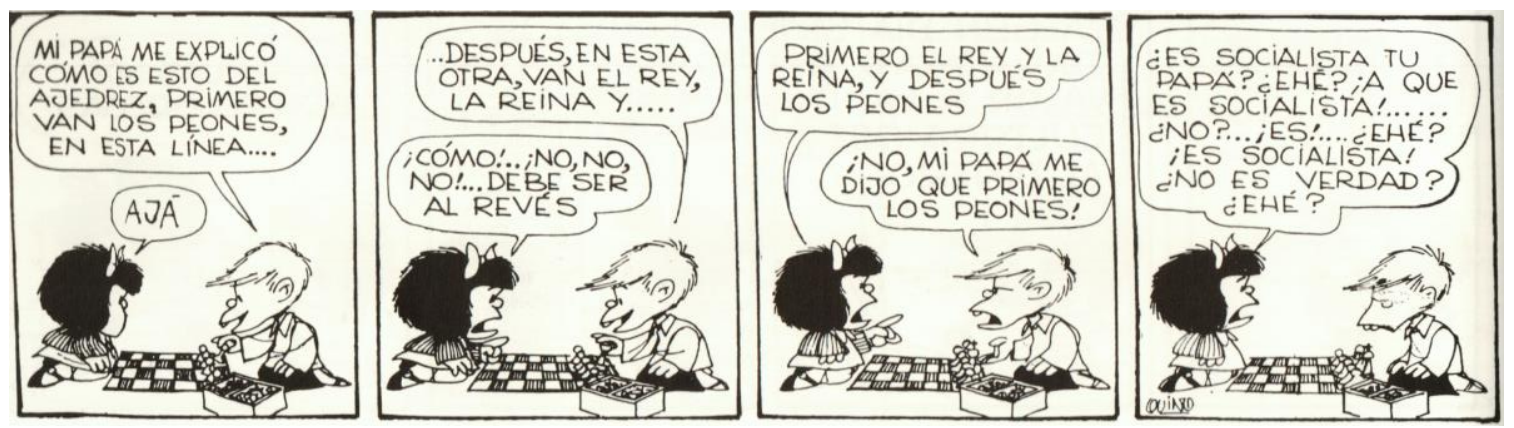

Referencia: Quino, Todo Mafalda, Barcelona, Lumen, 2003: 64.
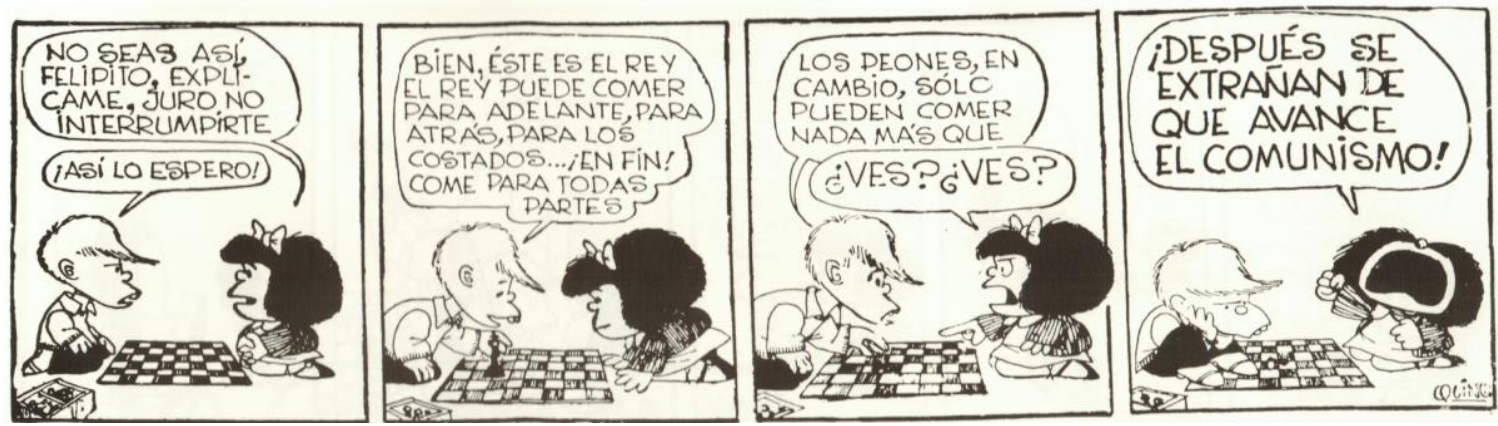

Referencia: Quino, Todo Mafalda, Barcelona, Lumen, 2003: 65.

El juego no deja de ser una parte de la vida. Por otro lado, el juego se desarrolla con total seriedad. Aunque leemos suspendiendo nuestra incredulidad, en cierto modo utilizamos nuestro sistema de valores, nuestras creencias acerca del mundo y nuestras experiencias 
previas para ir rellenando lo que no viene explicitado en el texto y construir su-nuestra realidad. En esta construcción pesa el ruido de fondo que haya en nuestra cabeza a lo largo de la lectura. Si Mafalda no estuviese obsesionada con la situación política del globo, si no supiese los términos «comunismo» y «socialismo», no los traería a colación en su interpretación acerca de la ideología dominante que transmite el ajedrez.

$* * *$

Por otra parte, ni el juego ni la poesía cumplen una función vital, como señala Rafael Núñez (1992b). Por eso el desempeño en el juego es intrascendente, por eso son actividades desinteresadas. En ese sentido, el jugador juega «por jugar», sin ninguna meta más allá del lapso temporal del juego, y su desempeño en el mismo, aunque tomado con la mayor seriedad, no debería afectarle más allá de los confines de esa práctica libre. Desde esta perspectiva, perseguir los efectos del juego, intentar reproducir su función antropológica de manera forzada, lo convierte en una cuestión problemática y difícil.

A veces una de las reglas del juego es fijar bien sus propios límites, enfatizando que el jugador tiene un fin dentro de los confines del juego, que no tendrá repercusiones más allá del mismo. Es lo que permite la búsqueda de sentido en la interpretación de un texto, que se percibe como unidad con sentido interno. Buscar significado más allá, asignarle una función extratextual, un sentido que sobrepase los confines de la interpretación, puede ser problemático, desde este punto de vista. Hace difícil el juego, lo eleva a una complejidad que en principio no tiene, y muchas veces lleva a la insatisfacción. Y ya no es lo de la miel y el hocico del asno, es decir, el elitismo que parece sobrevolar el campo de la cultura y según el cual sólo algunos pocos tienen la capacidad para acceder a la correcta interpretación de los textos literarios: son el centenar de pájaros volando allá a lo lejos comparadas con el anodino periquito doméstico de la abuela, que tanta compañía le da, en busca de explicaciones contextualizadas a partir de datos que no están a disposición de cualquier lector, sino sólo (otra vez) de esa élite culta que lee estudiando, buscando, indagando en biografías, periodizaciones y exégesis críticas y autoriales que permitan mostrar el sentido de la obra. 
Convertir el libro en un criptograma que precisa de investigación externa para ser correctamente descifrado redunda en un problema socio-económico, en la medida en que no todos disponemos del mismo tiempo ni del mismo bagaje como para dedicarnos a indagaciones extraliterarias. Pero es que, analizada en profundidad, esta cuestión puede alcanzar dimensiones políticas, puesto que se establece una relación asimétrica entre quienes dictaminan que una interpretación es correcta y quienes se ven forzados a acatar esta lectura en base a unos documentos y datos externos que no conocen de primera mano. En el ámbito de la interpretación literaria, la cuestión parece baladí: pero si ponemos esta disciplina junto a otras afines (aquellas que deseché antes por estar relacionadas con la «verdad» y que me parece ahora que de algún modo cumplen una función más «ceremonial» y aparentemente decisiva para la vida del individuo: la interpretación de textos religiosos, la interpretación legal, la interpretación científica...) asoma el peligro.
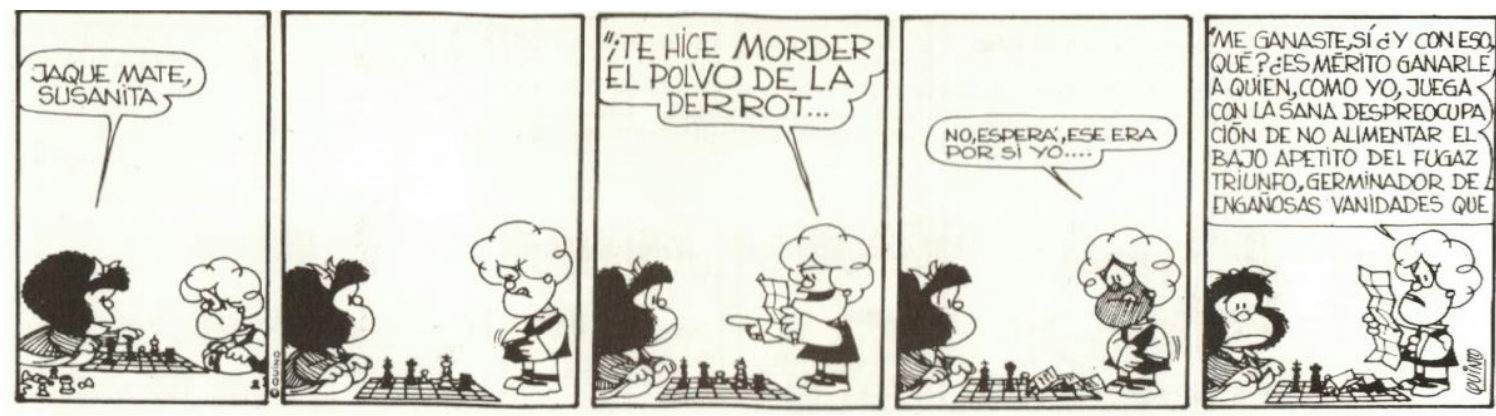

Referencia: Quino, Todo Mafalda, Barcelona, Lumen, 2003: 482.

Y aun con esta conciencia de que el juego es «solo» eso, la cosa se ha ido retorciendo tanto que ganar una partida de ajedrez puede convertirse en una afirmación del propio estatus intelectual y de la superioridad estratégica sobre el contrario. También puede tener efectos psicológicos, y económicos, e incluso puede adquirir una trascendencia mayor. Y no digamos lo que puede significar perder una partida. Que se nos acuse de no haber entendido tal texto central para la comprensión de nuestra identidad patria, o que se nos tache de incultos por disfrutar leyendo cosas que, desde un punto de vista ilustrado, son menores, poco interesantes $\mathrm{o}$, ya, en un polo extremo, que se nos censure o persiga por poseer libros que alguien encuentra inadecuados, incorrectos o dañinos. Sería deseable mantener el juego como juego y la interpretación literaria como interpretación literaria desproveyéndolos de juicios de valor, pero no siempre es fácil.

$* * *$

Cabe afirmar que siempre leemos desde una ideología. A veces puede ocurrir que los prejuicios de quien se enfrenta a un texto literario sean tan grandes y estén tan 
fundamentados que el lector vaya chocando con la realidad (opalescente) de la escritura con un coeficiente de rozamiento demasiado alto. Que no logre penetrar en la ficción sino mediante un esfuerzo demasiado grande. O que la ficción le propulse hacia afuera. Que su «vigilancia epistémica», en palabras de Wilson (2018), le impida admitir lo que se está narrando. Hablo de un conflicto ético.

A este respecto hay multitud de opiniones acerca de lo que es adecuado que haga el lector: Marta Sanz da cuenta de algunas posturas posibles en el ensayo de cierre de Monstruas y centauras, en donde aclara que, igual que hay textos con distintas ideologías, hay lecturas impregnadas por diferentes actitudes — «lecturas devotas, esteticistas, pseudoingenuas, maligno-ingenuas y raramente ingenuas, lecturas chill-out y perversas, lecturas reaccionarias, escandalizadas, fantasiosas, adolescentes, eruditas, políticas... Lo peor son las lecturas -también las escrituras- perezosas y mecánicas» (2018: 117)—. La cuestión aquí está en la ética del lector y en que esta ética le permita enfrentarse a la lectura sin despojarse de sus prejuicios, pero aceptando los hechos y las opiniones atisbados en el texto. Lo suyo sería conseguir construir una identidad de lector camaleónico -lector, poeta: cronopio-, que diría Cortázar (1970 [1967]) de ser capaz de jugar a la lectura viviendo los diferentes colores.
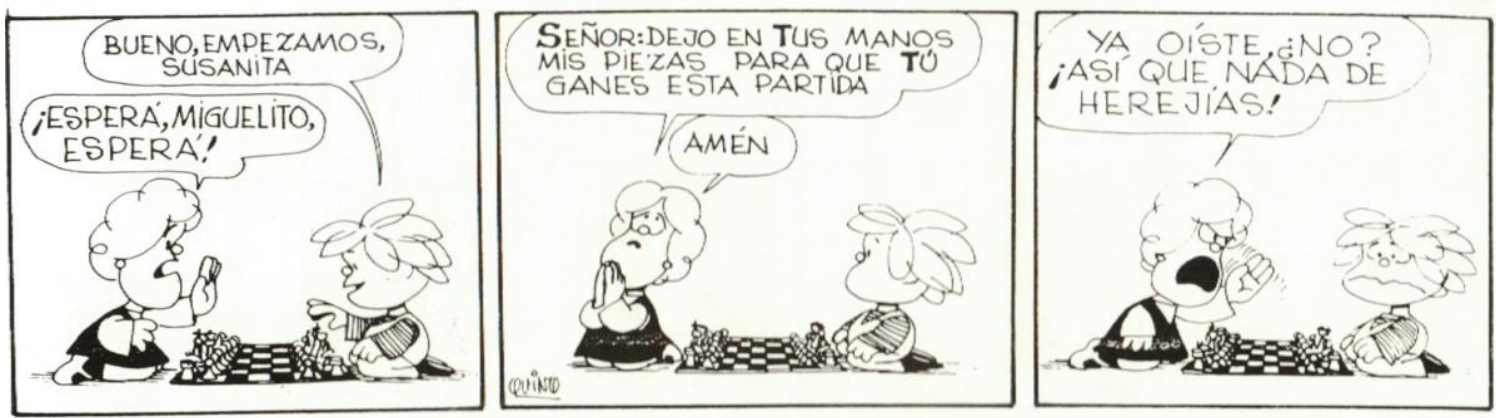

Referencia: Quino, Todo Mafalda, Barcelona, Lumen, 2003: 201.

Aunque a nivel teórico esta reflexión parece difícilmente discutible, la práctica de disfrutar de la lectura tarda en desarrollarse, y en ocasiones el enfado del lector contrariado supera su buena disposición. La sensación constante de ataque causada por la obra de un pensador con el que disiente le expulsa de la lectura. A mí me pasó con la idea del propio Cortázar del «anillo de musgo» en el Libro de Manuel (novela que encuentro genial y nada panfletaria, contra lo que pensaba su autor). «El anillo de musgo» es la cita con que un colega y yo nos referimos a ese pasaje de la novela en el que una violación anal es representada como símbolo de ruptura de tabúes y de pensamientos rígidos. Mantengo mi indignación como un pequeño picor del entrecejo, en el plano del «yo sé que esto tendría yo que ser capaz 
de leerlo sin gruñido reprobador, pero aún no soy capaz, y está bien». Y luego me ha ido pasando con otras cosas que soy capaz de entender pero que se me «contracturan». Como el concepto de «lector hembra», que entre muchos otros autores utiliza el propio Cortázar para referirse a los lectores perezosos, como yo, frente a los «lectores macho», cerebrales y trabajadores (entre los cuales seguro que se pueden encontrar muchas hembras: la asociación de ambos roles lectores con los dos sexos es perversa). Cortázar me causa pequeñas incomodidades éticas. En todo caso, pienso que forzarse a leer lo que no se quiere leer solo lleva a indigestar y confundir al monstruo intérprete.

Volviendo al contexto didáctico, benditos sean los alumnos porque a veces nos hacen pensar las cosas desde otro punto de vista. Creía que este anticensurismo era muy chick, y de pronto me devino demodé. Recuerdo una ocasión en que, en una clase estaba intentando exponer esta perspectiva desde la cual la censura por motivos éticos de obras cuyo potencial estético es elevado no me acababa de convencer. Y hablaba yo de juicios populares, y de Polanskis, y de Allens, y de Haséles, y de Spaceys, y en otro plano de Minority Report (y por tanto de Philip K. Dick, también, y de I Love Dick, ya de paso). Sacaba temas conflictivos, actuales y no del todo claros porque me parece que dan más juego: de Nabokov y su Lolita ya se ha dicho mucho. Y entonces mis alumnos aludieron a la cuestión económica. «Hasta qué punto está bien que le demos una recompensa económica a esta persona que está viva o a este producto que sigue produciéndose y que, sospechamos, no está haciendo ningún bien al estado de cosas actual». Claro: cómo conjugar mi intento de bajar la vigilancia epistémica en todo lo estético con la preocupación económica de no comprar cosméticos testados en animales, no consumir productos que no sean de comercio justo y evitar todo lo que pueda dañar el medioambiente. Pues es difícil.

\section{$* * *$}

El fondo de esta cuestión tiene que ver con una percepción que considero bastante acertada y que, muy simplificada, se resume en la siguiente afirmación: el arte influye en la vida. 

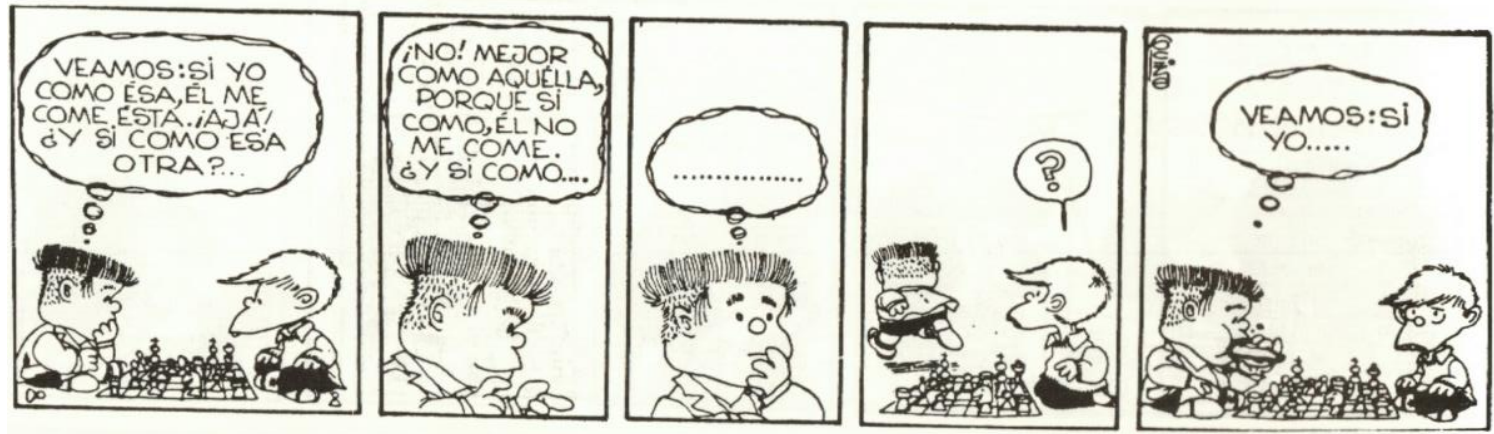

Referencia: Quino, Todo Mafalda, Barcelona, Lumen, 2003: 82.

Y no siempre lo hace de la manera en la que esperaban sus autores que lo hiciesen. El «significado» puede ser extraído de distintos estratos de la obra literaria. Este monstruo nuestro tiene la capacidad de seleccionar con finura y un poco distraídamente la capa de la cebolla que más le apetece para recocerla y recocinarla y deconstruirla y hacer un plato exquisito y jugoso que comer a solas o con otros. Un sainete de cebolla frita. Hay teóricos que piensan que, en esa labor de chef todopoderoso, el monstruo necesariamente tiene que reconocer que esa cebolla existe debido a la voluntad de alguien. Es decir, que hay algún tipo de autor, aunque sea ideal, aunque sea percibido sólo como alguien que tiene la voluntad de decir algo y «autoridad» para decirlo (aunque no sepamos qué algo es ese).

Yo a esto lo llamo «la hipótesis del sainete de manitas fritas», porque tanto Eco (1992 [1990]) como Núñez y Lorenzo (2004) apelan a este ejemplo. El punto de partida de esta teoría siempre es un experimento mental: imaginemos hay una máquina con capacidad para «crear» oraciones. Una máquina con una gramática y con un programa que le permite sintetizar metáforas. Seguramente creará metáforas que seremos capaces de interpretar. Pero también habrá metáforas no tan fácilmente interpretables, como «sainete de manitas fritas». Núñez y Lorenzo argumentan que lo que sucede es que la obra artística no cobra sentido hasta que no es experimentada, o interpretada, y el primer intérprete que le otorga esta entidad es el autor, que se autoobserva. Yo, que estoy hablando de interpretar como co-crear, digo que el lector también tiene puede arrogarse esta responsabilidad de dar por terminado. También el lector puede coger las riendas de su interpretación y usar las palabras del autor de forma interesante. De ahí el interés del @MagicRealismBot que, igual que el ordenador que juega al ajedrez contra nosotros en un simulador, es capaz de imitar una parte de este juego de la literatura para permitirnos re-co-crear sainetes de manitas (o de cebollas) fritas. Nos hace, de este modo, ahondar individualmente en un juego que usualmente se desarrolla en pareja, y nos permite entrenarnos y sorprendernos ante lo mecánico de nuestra comprensión. 
Evidentemente, este tipo de usos voluntaristas hace patente cómo la responsabilidad sobre «lo dicho» no puede imputarse al «autor». O no solamente. Podría parecer que la existencia de un lector consciente y dispuesto a crear (un «macho» cortazariano), desautoriza al autor. Lo reduce a mero enunciador de un sentido que sólo está en potencia. En la ficción no pesa tanto el significado supuestamente inherente (el significado $^{\text {DRAE }}$ ) de las palabras como el significado otorgado, el uso que se hace de las mismas. El problema de la interpretación literaria es que los expertos obsesionados con recuperar el significado original y verdadero de los términos à la Putnam (1984 [1975]) no han alcanzado un método único y definitivo, y las distintas escuelas están en continua discusión a este respecto.

El conflicto reside en que este significado, desde lo que yo trato de exponer, al ser co-creado, también tiene una parte de lo que el intérprete le coloca encima. Es el resultado de un juego en pareja. Como se suele decir al hablar de relaciones humanas, el lector lleva una mochila, va acumulando un equipaje emocional que no puede quitarse tampoco para su interacción con el texto. Dice Dewey (1980 [1934]) que el pensamiento va en trenes de ideas: una se junta a las anteriores por el final, y coge el impulso que estas llevaban; la experiencia (la lectura) también tiene este formato de trenecito. El licor destilado por una inteligencia $\mathrm{x}$ y contenido en el texto está ahí, envejeciendo y tomándose de sabor en su botella: pero el que agarra el sacacorchos hermenéutico para llegar a él es el lector.

El grado de responsabilidad evidentemente crece cuando el intérprete toma conciencia de su voluntarismo co-creador.
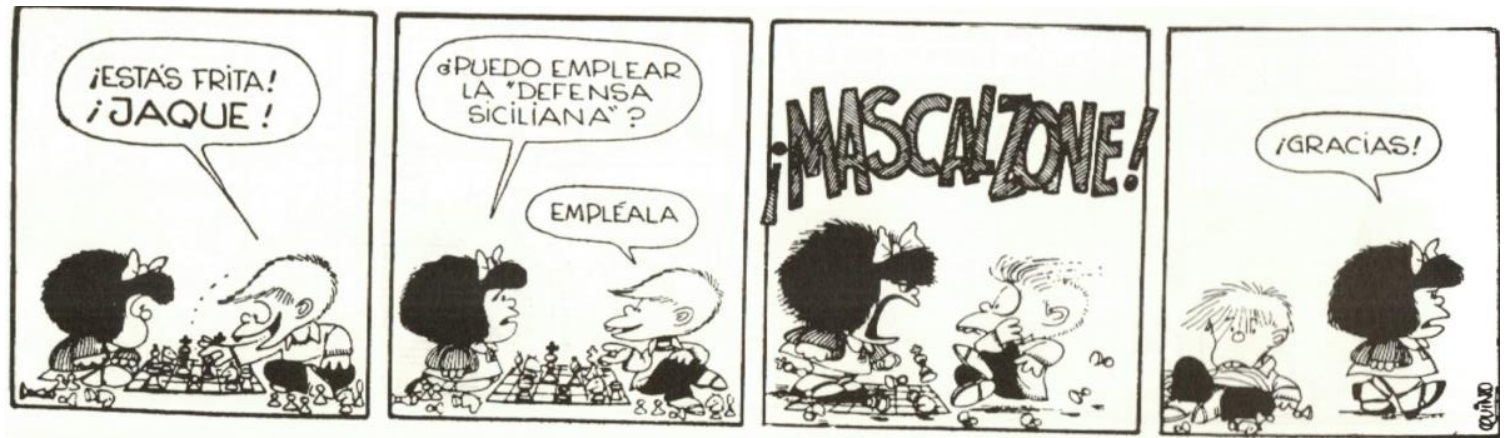

Referencia: Quino, Todo Mafalda, Barcelona, Lumen, 2003: 82.

Cuanto más deformamos las reglas en provecho de lo que queremos obtener de una lectura, menos podremos culpar luego al autor, o a las reglas, o al texto, de lo que ha resultado de nuestra interpretación. Por ejemplo: en el ejercicio-práctica-uso que yo estoy haciendo de las viñetas de Quino (y que, diría Eco, no es una interpretación... pero dónde está el límite entre interpretación y uso) no debe uno buscar en la intención del autor ni en las 
viñetas en sí lo que yo estoy diciendo, que es una misinterpretation premeditada y rebuscada (aunque posible). Las representaciones más perezosas e irresponsables me parecen las más probables, pero las aproximaciones hiperactivas al texto, los arriesgados all-in y las trampas a la banca, ya lo he dicho, también pueden darse. Y a veces dan en la diana, como la «LYRICA®» de García Rodríguez (2016), un ejercicio de lectura voluntarista que consigue extraer de un prospecto médico reflexiones interesantes sobre el género lírico. Solo hay un requisito: cuando corremos estos riesgos y los guardas intentan expulsarnos del casino, tenemos que ser capaces de dar la cara y admitir nuestra parte de culpa.

Quiero acabar haciendo un pequeño homenaje a los monstruos que, como el mío, llevan bolsito. Son monstruos modestos, utilitaristas, curiosos, que no compran en Glovo porque disfrutan yendo al mercado y parándose a leer las etiquetas y charlar con los vecinos. Monstruos que pasean por largas estanterías y van poniendo en su bolsito cosas que se encuentran por ahí: cartas de tarot, fotografías, oraciones, sueños, chascarrillos. Y con todas esas cosas se construyen sus historias.

Ursula K. Le Guin, en un ejercicio de reflexión acerca de cómo se construyen las ficciones en el mundo occidental, distingue las ficciones «flecha», que pretenden hendir, incidir, transitar un camino recto desde el inicio hasta el fin hiriendo con la espada de un héroe todo impedimento que interrumpa la narración, y las ficciones de «bolsito» (1989 [1986]). En estas últimas, el narrador va metiendo cosas en un continente, recolectando pequeñas historias, creando una antropología de ama de casa que carga con el pintalabios, las llaves, el adoquín, los guantes, el spray antiviolación, los preservativos y todo lo que ha ido depositando en la saca un día de paseo por la cultura contemporánea.

Creo que también hay intérpretes cazadores e intérpretes de bolsito. Lectores lineales y lectores deambulantes. Expedicionarios y flâneurs. Penetradores del texto y parteras que le ayudan a alumbrar nuevas creaturas $^{3}$ diferentes del texto en sí. Están los que necesitan contar su historia a través de lo leído y los que escuchan aquello que les cuentan a ratitos, mientras hacen otra cosa. Los que ven en el texto una excusa para saber (aprehender) algo y los que leen porque leen y, de paso, saben.

Mi sentir es que, ahora mismo, nuestros jóvenes (y nosotros mismos) no tenemos tiempo para ponernos a rastrear presas, pero no por ello hemos perdido las ganas de comer.

3 Término de Jung que he aprendido recientemente gracias a Bateson (2002). 
En el proceso de localizar el animal al que le vamos a tender la trampa nos despistan la multitud de manadas de conejos y piaras de elefantes que campan por nuestro entorno cultural: teleseries, videojuegos, juegos de rol... Otro tipo de ficciones atractivísimas. Por otra parte, se supone que tanta sobreexposición a la imagen animada nos ha hecho demasiado impacientes y descentrados.

En una ocasión, en un congreso, un teórico literario de cierto renombre (otro académico más académico que yo) me dijo, no sin razón, que el significado originariamente pensado por un autor para su texto es accesible, y es en esencia el único significado del texto. Según las reglas de juego que a él le habían enseñado y que tan doctamente quería transmitirme, este significado podía recuperarse gracias a la filología. El argumento que él esgrimía venía a implicar que, por medio de un proceso quirúrgico, es posible extraer la vida del cadáver textual sin que esta se vea contaminada por las miasmas que flotan por el quirófano. Quizás por esta vagancia que he dicho que tengo, por falta de tenacidad o por pura incapacidad, yo nunca he sido capaz de mantener mi mesa de operaciones tan limpia como para que esa contaminación no se produzca. Así que, incluso si me interesase la caza, en el proceso de despiezar el animal muerto, de limpiarle las vísceras y de analizar su grupo sanguíneo y el contenido de su estómago, es posible que echase a perder la pieza. Valga con recordar que esta forma de leer literatura existe y tiene un cierto valor, por más que yo no la defienda. Es necesario apuntar que no es la única, y que en este afán de descubrir e ilustrar, el filólogo se arriesga a convertirse en un Carl Akeley de las letras: un creador impositivo de significados estáticos, cargados de ideología; y en tal caso estaría bien que se someta a sí mismo a autoexamen ${ }^{4}$.

Pero ¿no es posible otro tipo de filología? Recuperando el sentido etimológico del término, ¿no se puede amar la palabra e interesarse por ella sin someterla constantemente al tercer grado? Creo que el ritmo de los tiempos exige que, para interesar a más alumnos en el cuidado de la literatura, tratemos de hacer esta práctica un poco más inclusiva. Que en nuestros programas docentes no distingamos el fomento de la lectura y la educación literaria (eufemismo agradable para referirse a la historia de la literatura nacional), sublevando el primero a la segunda: que leamos cosas (que nos lean cosas) recolectadas de aquí y de allá y que expliquemos por qué esas cosas, de dónde vienen, qué nutrición aportan, cómo sustentan

4 A título personal, recomendaría a todo filólogo leer El patriarcado del osito Teddy, aunque solo sea para reflexionar acerca de cómo selecciona los textos que analiza, cómo los trata, qué hace con ellos... y cómo su labor contribuye a mostrar a los inexpertos lectores qué es la Literatura. 
el estatus cultural, y qué valor le otorgamos nosotros a ese desempeño del comer que tantas facetas tiene (nutricional, lúdica, cultural...). ¿Y si dejamos que nuestro papel docente pase al del mediador que, dice Sell (2000), hace a sus alumnos partícipes de una literatura humanizada e históricamente situada (pero no historicista)? En tal caso dejaremos de dedicarnos a esta tarea tan ardua de leer de principio a fin todo lo escrito en nuestro coto de caza para ir seleccionando conjuntamente con nuestros alumnos lo que más nos apetezca. Y, para hacerlo, nos pertrechamos con las herramientas que más nos convengan, siguiendo las reglas del juego que cada uno se traiga de su casa. Luego debatiremos, si acaso sobre cuáles son los resultados obtenidos y qué valor les asignamos.

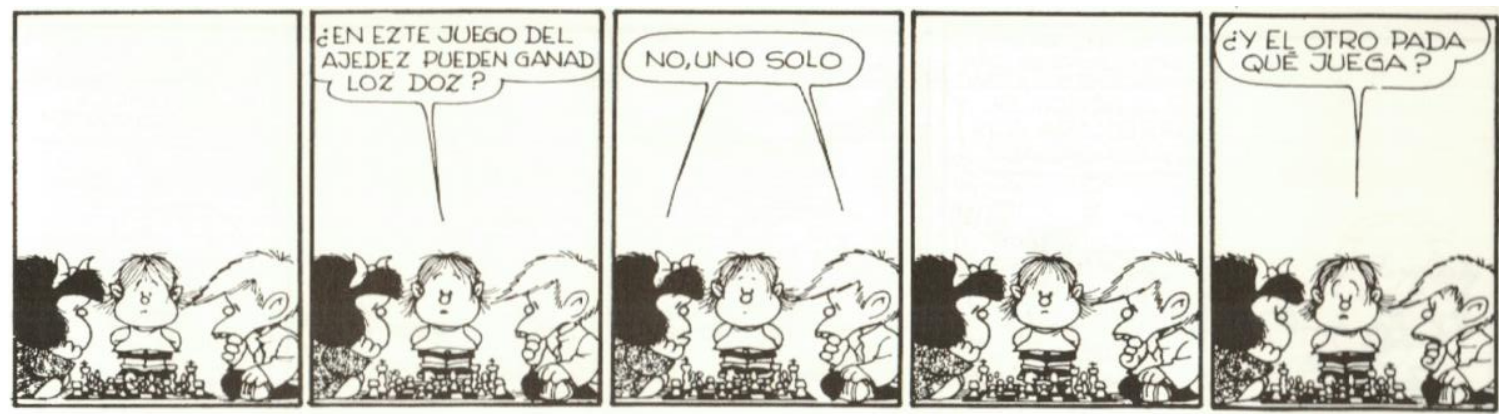

Referencia: Quino, Todo Mafalda, Barcelona, Lumen, 2003: 405.

Abría este artículo con el título «el juego de la deriva continua» sin demasiada convicción sobre lo que iba a plantear después, con una preocupación más didáctica que teórica. En esta idea se contenía mi voluntad de expresar la multitud de aproximaciones posibles que pueden hacerse a un texto o un concepto (como lo es el concepto de interpretación, por ejemplo). La idea de la «deriva continua» o de la «semiosis ilimitada» está muy presente en el Eco de Los limites de la interpretación (texto del que tomo la expresión con que encabezo el artículo, 1992 [1990]: 158). Pero la idea del juego vinculado a la deriva continua también impregna «La estructura, el signo y el juego en el discurso de las ciencias humanas», de Derrida (1989 [1967]). El juego es para el autor francés la no-totalización, el infinito que no se puede captar en una mirada, en un discurso acotado. Y yo lo tomo aquí como una metáfora de esa raicilla que se reproduce fractalmente, que germina en una continuidad inacabable de traducciones cuyo eje se va alejando, poco a poco, del punto de origen, diferenciándose en la eterna repetición. Interpretar es, en definitiva, un ejercicio de renovación creativa. 


\section{BIBLIOGRAFíA}

Bateson, Gregory (2002): Espiritu y naturaleza, Buenos Aires, Amorrortu Editores.

Brockman, John (1995): The Third Culture: Beyond the Scientific Revolution, New York, Simon \& Schuster.

Cortázar, Julio (1970): La vuelta al día en ochenta mundos. Tomo II, Madrid, Siglo XXI editores.

Danielewski, Mark (2014): La espada de los cincuenta años, traducción de Javier Calvo, Málaga / Barcelona, Pálido Fuego / Alpha Decay, S.A.

Derrida, Jacques (1989): «La estructura, el signo y el juego en el discurso de las ciencias humanas», en La escritura y la diferencia, traducción de Patricio Peñalver, Barcelona, Anthropos.

Dewey, John (1980): Art as Experience, New York, Perigee Books.

Eco, Umberto (1992): Los límites de la interpretación, Barcelona, Lumen.

Fish, Stanley (1980): Is There a Text in This Class? The Authority of Interpretive Communities, Cambridge / London, Harvard University Press.

García Berrio, Antonio (1994): Teoría de la literatura. (La construcción del significado poético), Madrid, Cátedra.

García Rodríguez, Javier (2016): «LyRiCA® (PATOlOGía y TRATAMIENTO)», Actio Nova: Revista de Teoría de la Literatura y Literatura Comparada, 0: 110-120.

Goodman, Nelson (1978): «The Fabrication of Facts», en W ays of Worldmaking, Indianapolis, Hackett Publishing Company: 91-108.

Huizinga, Johan (1972): Homo ludens, Madrid, Alianza Editorial.

Ingarden, Roman (2005): La comprehensión de la obra de arte literaria, traducción de Gerald Nyenhuis, México, Universidad Iberoamericana.

Iser, Wolfgang (2005): Rutas de la interpretación, México, Fondo de cultura económica.

James, Henry (1884): «The Art of Fiction», en Walter Besant and Henry James, The Art of Fiction, Boston, Cupples and Hurd: 49-85.

James, William (1922): Pragmatism, a New Name for some Old Ways of Thinking, New York/London, Longmans, Green and co.

Lakoff, George y Mark Johnson (2012): Metáforas de a vida cotidiana, Madrid, Cátedra.

Le Guin, Ursula K. (1989): Dancing at the Edge of the World. Thoughts on Words, Women, Places, New York, Grove Press. 
Nabokov, Vladimir (2010): Curso de literatura rusa, traducción de María Luisa Balseiro Fernández-Campoamor, Barcelona, RBA.

Navarro Durán, Rosa (2004): Alfonso de Valdés, autor del Lazarillo de Tormes, Madrid, Gredos.

Núñez Ramos, Rafael y Guillermo Lorenzo González (2004): Tres cerditos. Uso, significado y metáforas, Oviedo, Universidad de Oviedo.

Núñez Ramos, Rafael (1992a): «El juego y la experiencia de los mundos posibles», en VV.

AA., Investigaciones Semióticas IV (describir, inventar, transcribir el mundo). Vol. 2, Madrid, Visor: 437-442.

Núñez Ramos, Rafael (1992b): La poesía, Madrid, Síntesis.

Putnam, Hilary (1984): «El significado de 'significado'», Teorema: Revista Internacional de Filosofía, XIII, 3-4: 345-406.

Quino (2003): Todo Mafalda, Barcelona, Lumen.

Sanz, Marta (2018): Monstruas y centauras. Nuevos lenguajes del feminismo, Barcelona, Anagrama.

Sell, Roger D. (2000): Literatures as Communication. The Foundations of Mediating Criticsm, Amsterdam / Philadephia, John Benjamins.

Shklovsky, Viktor (2005): Knights Move, traducción al inglés de Richard Sheldon, London, Dalkey Archive Press.

Wilson, Deirdre (2018): «Relevance Theory and Literary Interpretation», en Terence Cave y

Deirdre Wilson (eds.) Reading Beyond the Code. Literature \& Relevance Theory, Oxford, Oxford University Press: 185-204.

Wittgenstein, Ludwig (2012): Investigaciones filosóficas, traducción de Alfonso García Suárez y Ulises Moulines, Barcelona, Crítica. 
SOBRE LA AUTORA

\section{Claudia Sofía Benito Temprano}

Claudia Sofía Benito Temprano es graduada en Lengua Española y máster en Estudios Artísticos, Literarios y de la Cultura por la Universidad Autónoma de Madrid. Gracias al disfrute de una Ayuda para la Investigación en los Estudios de Máster otorgada por la UAM en el pasado y, actualmente, a una Ayuda de Formación para el Profesorado Universitario financiada por el Ministerio de Educación y Ciencia, ha podido ahondar en el estudio de la distopía y desde 2018 se encuentra desarrollando una tesis al respecto dirigida por Francisco Javier Rodríguez Pequeño. Sobre esta cuestión y otras afines (el género de ciencia ficción, la teoría de géneros) ha publicado artículos en revistas especializadas y libros colectivos.

Contact information: Universidad Autónoma de Madrid. claudia.benito@uam.es 